\title{
LEY DE EDUCACIÓN SEXUAL INTEGRAL
}

\author{
Proyectos de reforma: introducción de la ideología \\ de género y supresión del ideario institucional en colegios \\ de enseñanza pública no estatal (privados)
}

\section{COMPREHENSIVE SEXUAL EDUCATION LAW}

\author{
Reform projects
}

\author{
Dr. Eduardo Martín Quintana ${ }^{1}$
}

A los alumnos y ex alumnos del Seminario Mayor San José de la Arquidiócesis de La Plata.

Confío en sus oraciones.

\section{Resumen}

El autor estudia desde un punto de vista jurídico el nuevo proyecto de ley de educación sexual integral. Se considera su constitucionalidad, su referencia a la familia y a la Iglesia, y se expone la opinión de distintos Papas sobre el tema.

\section{Abstract}

Author study the new project of comprehensive sexual education law from a juridical point of view. He considers its constitutionality and its reference to the family and the Church and exposes the opinion of some Popes about the matter.

\footnotetext{
${ }^{1}$ Doctor en Ciencias Jurídicas.
} 


\section{Los padres y la educación de sus hijos.}

El ser humano es el más desvalido de todos los vivientes. No sólo necesita para sobrevivir atención de mayores para su sobrevivencia física (alimentación, etc.), sino a la vez un entorno de afecto y educación que posibilite el desarrollo armónico de todas sus facultades. Desde tiempo inmemorial hasta el presente, se encuentra demostrado que los padres y la familia son quienes mejor asumen esa función, la que sólo puede ser suplida en caso de abandono o graves falencias. Pero además, ya desde la antigüedad se expresaba que a partir de la familia la sociabilidad humana requería de asociaciones intermedias (entre ellas educativas) y finalmente de la presencia del Estado, como "sociedad de sociedades" cuyo fin es el bien común de todos sus integrantes. Sin perjuicio de ello, respecto a los niveles de enseñanza básica y secundaria, donde los educandos son niños o adolescentes o sea menores, los padres conservan el derecho de elegir el establecimiento educativo y en caso de las escuelas públicas, que clase de contenidos reciben sus hijos. Estos derechos se encuentran protegidos tanto en nuestra Constitución Nacional, como también en todos los tratados internacionales que se refieren al tema y que desarrollaré sintéticamente en estas líneas. En el espacio educativo, como en tantos otros, el Estado tiene una función subsidiaria y de supervisión del cumplimiento de los fines constitucionales, por lo tanto no debe asumir las tareas propias de las sociedades intermedias.

\section{Ley de Educación Sexual Integral (no menciona la palabra "genero")}

Según se establece en la ley (art. $1^{\circ}$ ) se entiende como "educación sexual integral la que articula aspectos biológicos, psicológicos, sociales, afectivos y éticos". Cabe destacar que no menciona en ninguna de sus disposiciones la palabra "genero", que como se dirá luego es el eje de la reforma que se propone. Agrego que tiene singular importancia lo que este cuerpo legal denomina "el diseño de las propuestas de enseñanza" y "la inclusión de los contenidos y didáctica de la educación sexual integral en los programas de formación de educadores", ya que en última instancia son ellos los lineamientos que recibirán los alumnos (art. $8^{\circ}$ ). De aquí la importancia que los establecimientos educativos privados puedan impartir la materia conforme a su ideario. Conforme a este principio, dispone que "cada comunidad educativa incluirá en el proceso de elaboración de su proyecto institucional, la adaptación de las propuestas a su ideario institucional y a las convicciones de sus miembros" (art. $5^{\circ}$ ).

\footnotetext{
${ }^{2}$ Ley $26.150,4 / 10 / 2006$, actualmente vigente.
} 


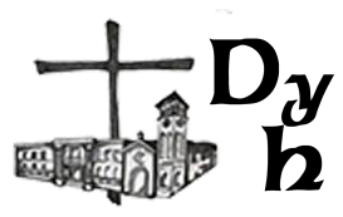

También debe tenerse en cuenta la disposición según la cual, "todas las jurisdicciones deberán organizar en los establecimientos educativos espacios de formación para los padres o responsables que tienen derecho a estar informados y vincular más estrechamente la escuela y la familia para el logro de los objetivos del programa" (art. $9^{\circ}$ ), ya que significa que los familiares directos participan del ámbito escolar y pueden estar al tanto de cuáles son los contenidos de la educación sexual que se les importe a los niños y adolescentes.

\section{Proyecto de reforma de la ley 26.150 de Educación Sexual Integral en la Cámara de Diputados del Congreso de la Nación y en la Legislatura de la Provincia de Buenos Aires.}

\subsection{Cámara de Diputados de la Nación.}

Se presentaron varios proyectos que recibieron un predictamen de las Comisiones informantes. Por tanto, a noviembre de 2018 aún no se ha iniciado el debate en el recinto. Excede el marco y objetivo de este trabajo analizar las numerosas modificaciones, por ello me referiré a las dos que considero más significativas.

a) Inclusión de la ideología de género ${ }^{3}$. Se modifica el artículo primero incluyendo la palabra "género" que como dije está ausente en la ley actualmente vigente. Sostiene que:

Todos los estudiantes tienen derecho a recibir educación sexual integral, respetuosa de la diversidad sexual y de género, con carácter formativo, basada en conocimientos científicos y laicos, en los establecimientos educativos públicos, de gestión estatal y privada, de las jurisdicciones nacional, provincial, de la Ciudad Autónoma de Buenos Aires y municipal. La presente ley es de orden público (art. $1^{\circ}$ ).

No deja de llamar la atención el término "laicos" pues si se refiere a conocimientos empíricos era suficiente la calificación precedente de "científicos".

b) obligación de impartir los contenidos curriculares elaborados por las autoridades del Estado sin tener en cuenta el ideario de los colegios. En efecto, la reforma propone que:

Cada institución educativa incluirá, en su proyecto institucional, a la Educación Sexual Integral de manera transversal y a través de espacios curriculares específicos. Los contenidos que hacen a la aplicación de la presente y de las resoluciones del Consejo Federal de Educación deberán incluirse en la currícula y modalidad de todos los niveles educativos de forma obligatoria, constituyéndose en disposiciones de orden público, independientemente

\footnotetext{
${ }^{3}$ Desarrollo el concepto de "ideología de género" en las citas del punto 5 de este trabajo.
} 
de la modalidad, entorno o ámbito de cada institución educativa, sea de gestión pública o privada (art. $5^{\circ}$ ).

\subsection{Cámara de Diputados Provincia de Buenos Aires (Proyecto aprobado a consideración de la Cámara de Senadores)}

Sigue los patrones de los proyectos de nivel nacional de lo que se deduce sin mayor esfuerzo que hay una fuente común a todos ellos:

La educación sexual integral científica, laica y con perspectiva de género será de carácter obligatorio como materia con espacio curricular propio y contenidos transversales en todos los niveles y modalidades del sistema educativo de la Provincia desde el nivel inicial hasta el nivel superior de formación docente, la educación técnica no universitaria, tomando en consideración la edad del educando con sentido de gradualidad y especificidad (art. $6^{\circ}$ ).

Con mayor elocuencia que el proyecto nacional dispone que:

El organismo de aplicación estará a cargo de una Comisión integrada por representantes de la Dirección General de Educación, Centros de Estudiantes de las Escuelas Secundarias e Institutos Terciarios, sindicatos docentes, representantes de organizaciones defensoras de los derechos de las mujeres y de la diversidad sexual y de género.

Como puede advertirse, los directivos de cada establecimiento, los padres y las familias desaparecen del panorama escolar. La composición de este organismo de aplicación fue calificada periodísticamente como irrazonable, "pues además que se pueden proponer candidatos mucho más calificados, lo que más asombra es la falta de toda mención sobre la comunidad educativa, formada por padres y maestros, considerados los más idóneos para decidir sobre la educación sexual de los chicos en edad escolar" (Editorial, 2018).

\subsection{Ataque frontal y agravios a la Iglesia Católica.}

Los fundamentos del proyecto aprobado por la Cámara de Diputados de la Provincia de Buenos Aires explicita claramente su blanco de ataque y hace recordar la fase de los muchos ilustrados franceses del siglo dieciocho que descargaban su odio a la Iglesia y Dios bajo el lema "écrasez l'infâme":

Las instituciones confesionales presentan la situación más grave ya que la ley 26.150 autoriza a las iglesias a dictar la educación sexual según sus preceptos obscurantistas, prejuiciosos y discriminadores.

La Iglesia Católica es hoy quien encabeza la resistencia a la legalización del derecho al aborto valiéndose de su lugar privilegiado como Estado dentro del Estado. Ante las prácticas binarias que llevan a la invisibilidad de la heterodisidencia, la homosexualidad, las infancias y adolescencias trans y problemáticas como el aborto y el embarazo adolescente los y las estudiantes 


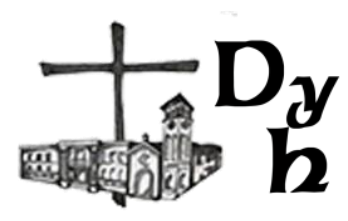

denuncian una falta de educación sexual que abarque todas estas cuestiones de manera crítica, científica y con perspectiva de género.

La finalidad de la reforma es "desarrollar una sexualidad plena y permitir el desenvolvimiento de una crítica a cómo se expresa en las relaciones entre las personas en el presente de nuestra sociedad. Una toma de conciencia a través del debate con un abordaje laico y científico y la crítica a toda perspectiva religiosa, oscurantista, opresora, discriminatoria, coercitiva o explotadora en la sexualidad y a toda forma de abuso y violencia sexual".

\section{Inconstitucionalidad de los proyectos de reforma de la ley de Educación Sexual Integral (26.150).}

Como lo he advertido en otras publicaciones, desde hace tiempo nuestro país padece un proceso de desinstitucionalización en los más altos niveles del Estado, que se refleja en que no se ciñen al rol que les corresponde, en el caso que nos ocupa el poder legislativo hace caso omiso de expresas disposiciones de rango superior contenidas en la Constitución Nacional (Quintana, 2018). Sin mayor ahondamiento mencionaré las normas que rigen la materia cuyos parámetros son dos: libertad de los ciudadanos y derechos de los padres y de la familia por sobre el poder del Estado, con la limitación que estos incumplan a la vez otra disposición de la carta magna lo que no sucede en el caso.

El art. 14 consagra entre otros el derecho de enseñar y aprender precedido por el derecho a profesar libremente su culto, que se encuentra fuertemente imbricado pues resulta difícil vivenciar una concepción religiosa cuyos preceptos se encuentran colisionados por una enseñanza no sólo distinta sino claramente agraviante. Por otra parte el art. 19 referido a la sanción de leyes que consoliden la unidad nacional expresamente menciona entre sus elementos "la participación de la familia y la sociedad".

La referencia explícita a los derechos de los padres respecto a la educación de sus hijos tiene su más firme y clara expresión en los tratados internacionales incorporados con rango constitucional en el art. 75 inc. 22. Entre ellos mencionaré:

\section{Declaración Universal de Derechos Humanos:}

Toda persona tiene derecho a la libertad de pensamiento, de conciencia y de religión... así como la libertad de manifestar su religión o creencia, individual y colectivamente, tanto en público como en privado por la enseñanza, la práctica, el culto y la observancia (art. 18).

Los padres tendrán derecho preferente a escoger el tipo de educación que habrá de darse a sus hijos (art. 26 inc. 3).

\section{Convención Americana de Derechos Humanos:}


Los padres, y en su caso los tutores, tienen derecho a que sus hijos o pupilos reciban la educación religiosa y moral que esté de acuerdo con sus propias convicciones (art. 12 inc. 4).

\section{Pacto Internacional de Derechos Civiles y Políticos:}

Los Estados Partes en el presente Pacto se comprometen a respetar la libertad de los padres $y$, en su caso, los tutores legales, para garantizar que los hijos reciban la educación religiosa y moral que esté de acuerdo con sus propias convicciones (art. 18 inc 4).

\section{Pacto Internacional de Derechos Económicos, Sociales y Culturales:}

Se debe conceder a la familia, que es el elemento natural y fundamental de la sociedad, la más amplia protección y asistencia posibles, especialmente para su constitución y mientras sea responsable del cuidado y educación de los hijos a su cargo (art. 10 ap. $1^{\circ}$ ).

\section{Convención Internacional sobre los Derechos del Niño:}

Las cuestiones vinculadas con la planificación familiar atañen a los padres de manera indelegable de acuerdo a sus principios éticos y morales (Reserva de la República Argentina al art. 24 inc. f).

Como corolario de este acápite me referiré a expresiones de uno de los más grandes constitucionalistas que tuvo el derecho argentino, José Manuel Estrada, quien a fines del siglo dieciocho fue el adalid de la lucha librada contra el liberalismo ideológico y la masonería. Afirma que:

Los padres tienen el pleno derecho a escoger las doctrinas bajo las cuales sus hijos han de ser educados y los maestros a los cuales han de confiar su educación. Para nuestro sistema constitucional la iniciativa, la responsabilidad y el gobierno corresponde a los padres de familia, a diferencia de los sistemas estatistas, en los que los niños son pupilos de la escuela, los padres son pupilos del gobierno, los municipios educacionales pupilos del Estado y aunque con menos grosería que en Esparta, el papel de la familia queda destruido por el imperioso social y absoluto del Estado cuyo papel en materia de enseñanza es puramente subsidiario o sea debe intervenir cuando los particulares y otras asociaciones no pueden hacerlo (Estrada, 1927, pág. 247).

\section{La ideología de género: San Juan Pablo II, S.S. Benedicto XVI y S.S. Francisco.}

Desde que hicieron su aparición diversas ideologías cuya finalidad ha sido licuar la imborrable impronta sexual del ser humano para convertirla en un uso discrecional alejado de todo parámetro objetivo, destruyendo entre otras cosas la perdurabilidad de la familia, los tres últimos pontífices han sido 


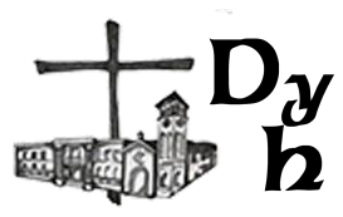

explícitos en advertir su deletérea expansión. Son innumerables los textos, por tanto la elección ha corrido a mi arbitrio ${ }^{4}$.

\section{San Juan Pablo II:}

Pienso, por ejemplo, en las fuertes presiones del Parlamento Europeo para que las uniones homosexuales sean reconocidas como una forma alternativa de familia, a la que correspondería incluso del derecho de adopción. Es lícito e incluso preguntarse si no sigue operando ahí una nueva ideología del mal, quizá más sutil y encubierta que intenta aprovechar los derechos del hombre contra el hombre y contra la familia (Juan Pablo II, Memoria e identidad, 2005).

\section{S.S. Benedicto XVI:}

Según Simone de Beauvoir "mujer no nace, se hace". En estas palabras se expresa la base de lo que hoy se presenta bajo el lema "gender", como una nueva filosofía de la sexualidad. Según esta filosofía, el sexo ya no es un dato originario de la naturaleza, que el hombre debe aceptar y llenar personalmente de sentido, sino un papel social sobre el que se decide autónomamente, mientras que hasta ahora era la sociedad la que decidía. La falacia profunda de esta teoría y de la revolución antropológica que subyace en ella es evidente. Niega la propia naturaleza humana y decide que esta no se le ha dado como hecho preestablecido, sino que es él mismo quien se la debe crear... Hombre y mujer como realidad de la creación, como naturaleza de la persona humana ya no existen. El hombre niega su propia naturaleza. Ahora es sólo espíritu y voluntad. La manipulación de la naturaleza, que hoy deploramos por lo que se refiere al medio ambiente, se convierte aquí en la opción de fondo del hombre respecto a sí mismo (Benedicto XVI, Discurso de felicitación de Navidad a la Curia Romana, 2012).

\section{S.S. Francisco:}

Otro desafío surge de diversas formas de una ideología, genéricamente llamada gender, que niega la diferencia y la reciprocidad natural de hombre y de mujer. Esta presenta una sociedad sin diferencia de sexo y vacía el fundamento antropológico de la familia. Esta familia lleva a proyectos educativos y directrices legislativas que promueven una identidad personal y una intimidad afectiva radicalmente desvinculadas de la diversidad biológica entre hombre y mujer. La identidad humana viene determinada por una opción individualista, que también cambia con el tiempo. Es inquietante que algunas ideologías de este tipo, que pretenden responder a ciertas aspiraciones a veces comprensibles, procuren imponerse como un pensamiento único que determine incluso la educación de los niños (Francisco, 2016, n56).

\footnotetext{
${ }^{4}$ Me parece relevante tener en cuenta que el Catecismo de la Iglesia Católica expresa que los actos homosexuales son intrínsecamente desordenados ( $n^{\circ} 2357$ ) pero también que un número apreciable de hombres y mujeres presentan tendencias homosexuales instintivas. "No eligen su condición homosexual; esta constituye para la mayoría de ellos una prueba... Se evitará respecto a ellos todo signo de discriminación injusta..." (n²358).
} 


\section{Conclusión: pretenden que los hijos ya no son de los padres sino del Estado y ellos son el Estado.}

El objetivo de esta ideología dirigida ahora a vulnerar nuestra legislación para introducirse en los colegios, es metamorfosear la naturaleza humana (nunca podrán destruirla) mediante el ataque antropológico más profundo que se pueda realizar: disolver la sexualidad según deseos mutantes cuya consecuencia es la debilidad y/o desaparición de la familia, quedando así el individuo inerme frente al estado. Si bien son numerosas las raíces de los presupuestos que aquí denunciamos, no puede dejarse de lado que el objetivo es la destrucción de lo que llaman "sociedad opresora y obscurantista" y que ya en el siglo diecinueve fue asumida por la dialéctica marxista entendida como lucha de clases, proletariado contra burguesía. Quizá ante su fracaso, sobre todo en las regiones del mundo que dominaron autoritariamente durante décadas, ahora la estrategia ha cambiado de rumbo y la dialéctica que se ha instalado en el seno más íntimo de las relaciones humanas: hombre y mujer, donde según el arquetipo difundido y replicado por los medios, aquel es el opresor y esta la oprimida. Estas no son deducciones conspirativas de mi parte, sino expresiones de Federico Engels, socio intelectual de Carlos Marx:

El hombre es en la familia el burgués; la mujer representa en ella el proletariado... En cuanto los medios de producción pasan a ser propiedad común, la familia individual deja de ser la unidad económica de la sociedad. La guarda y educación de los hijos se convierte en asunto público; la sociedad cuida con el mismo esmero de todos los hijos (Engels, 1971, pág. 87).

\section{Bibliografía}

Benedicto XVI. (2012). Discurso de felicitación de Navidad a la Curia Romana. http://w2.vatican.va/content/benedictxvi/es/speeches/2012/december/documents/hf_benxvi_spe_20121221_auguri-curia.html.

Editorial. (11 de septiembre de 2018). Legislar para una educación sexual integral. La Nación, págs. https://www.lanacion.com.ar/2170764-legislareducacion-sexual-integral.

Engels, F. (1971). El origen de la familia, la propiedad y el Estado. Buenos Aires: Claridad.

Estrada, J. M. (1927). Curso de Derecho Constitucional (Vol. 1). Buenos Aires: Editorial Científica y Literaria Atanasio Martínez.

Francisco. (2016). Exhortación Apostólica Post Sinodal Amoris Laetitia. http://w2.vatican.va/content/francesco/es/apost_exhortations/documents /papa-francesco_esortazione-ap_20160319_amoris-laetitia.html. 


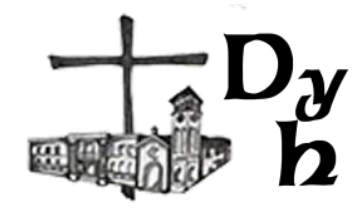

Juan Pablo II. (2005). Memoria e identidad. Madrid: La esfera de los libros.

Quintana, E. M. (2018). Incertidumbre actual del derecho y la seguridad jurídica.

En Anales de la Academia Nacional de Ciencias Morales y Políticas (Vol. 1). https://www.ancmyp.org.ar/user/FILES/3-QUINTANA.pdf. 